\title{
PROFIL DAYA TAHAN JANTUNG PARU, KEKUATAN OTOT PUNGGUNG, KEKUATAN OTOT TUNGKAI, FLEKSIBILITAS, KOMPOSISI TUBUH DAN SOMATOTYPE PEMAIN SEPAK BOLA U-17 ROMBERZ FC BANTUL YOGYAKARTA
}

\section{Oleh: Fatkurahman Arjuna dan Dwi Riyan Susanto* Dosen Jurusan Pendidikan Kesehatan dan Rekreasi FIK UNY}

\begin{abstract}
Abstrak
Penelitian ini bertujuan untuk mengetahui profil daya tahan jantung paru, kekuatan otot punggung, kekuatan otot tungkai, fleksibilitas, komposisi tubuh dan somatotype pemain sepak bola U-17 Romberz FC.

Penelitian ini merupakan penelitian deskriptif. Metode yang digunakan adalah metode survei dengan teknik pengambilan datanya menggunakan tes pengukuran. Penelitian ini merupakan penelitian studi kasus dengan subjek pemain Romberz U 17 yang berjumlah 21 pemain. Teknik analisis data yang dilakukan adalah menuangkan frekuensi ke dalam bentuk persentase.

Hasil penelitian ini menunjukkan bahwa daya tahan jantung paru pemain U-17 Romberz FC berada dalam kategori sedang yaitu sebanyak 9 pemain (42,86\%). Kekuatan otot punggung pemain U-17 Romberz FC berada dalam kategori kurang sebanyak 21 pemain $(100 \%)$. Kekuatan otot tungkai berada dalam kategori kurang sebanyak 10 pemain (47,62 \%). Fleksibilitas pemain U 17 Romberz FC berada dalam kategori cukup dan kurang, masing-masing sebanyak 7 pemain (33,33\%). Profil komposisi tubuh pemain U-17 Romberz FC yng berkaitan dengan indek massa tubuh berada dalam kategori berat badan normal atau ideal sebanyak 9 pemain $(42,86 \%)$. Lemak tubuh berada dalam kategori baik sebanyak 10 pemain (47,62 \%). Somatotype pemain U-17 Romerz FC berada dalam kategori tipe tubuh balanced ectomorph sebanyak 13 pemain $(61,90 \%)$.
\end{abstract}

Kata Kunci: daya tahan jantung paru, kekuatan otot punggung, kekuatan otot tungkai, fleksibilitas, komposisi tubuh, somatotype,

Ket *: Mahasiswa Prodi Ilmu Keolahragaan (Ikor) FIK UNY

Profil Daya Tahan Jantung Paru, Kekuatan Otot Punggung, Kekuatan Otot Tungkai, Fleksibilitas, Komposis Tubuh dan Somatotype Pemain Sepak Bola U-17 Romberz FC Bantul Yogyakarta (Dwi Riyan Susanto dan Fatkurahman Arjuna) 
Dalam permainan sepak bola sangat dibutuhkan kondisi fisik yang prima untuk menunjang keterampilan bermain sepak bola seperti kecepatan, dan kelincahan, daya tahan (M. Sajoto, 1988: 10). Tujuan permainan sepak bola sendiri yaitu memasukkan bola sebanyak-banyaknya ke gawang lawan dan mencegah lawan agar tidak bisa memasukkan bola ke gawang tim yang dibela. Untuk dapat bermain sepak bola dengan baik harus melakukan latihan yang teratur dan berkesinambungan. Latihannya juga tidak hanya mengenai teknik saja melainkan harus lebih kompleks terkait kondisi fisik dan mental. Hal tersebut merupakan subjek yang akan menentukan prestasi yang lebih cepat berkembang.

Prestasi puncak pada cabang olahraga sepak bola memerlukan latihan yang terprogram, kebugaran fisik yang baik, diperlukan pula bentuk tubuh atau anggota badan yang khas. Menurut Soeharsono (1993: 1), untuk pencapaian prestasi puncak bagi setiap cabang olahraga diperlukan bentuk tubuh yang khas. Menurut Sheldon yang dikutip oleh Kevin Norton dan Tim Olds (1996: 152), secara garis besar bentuk tubuh manusia dibagi ke dalam tiga tipe:

1. Tipe endomorph, yaitu tipe tubuh yang gemuk.

2. Tipe mesomorph, yaitu tipe tubuh yang besar dan kuat.

3. Tipe ectomorph, yaitu tipe tubuh yang kurus dan tinggi.

Ketiga tipe ini sangat besar pengaruhnya terhadap pencapaian prestasi dalam dunia olahraga pada umumnya dan persepakbolaan khususnya. Meskipun demikian umumnya bentuk tubuh manusia merupakan gabungan dari ketiga tipe di atas, tetapi besar pula kemungkinannya bahwa salah satu lebih dominan, (Yusuf Hadi Sasmita dan A. Syarifuddin, 1996: 23).

Berdasarkan pendapat-pendapat di atas dalam sepak bola sangat dibutuhkan kebugaran fisik dan bentuk tubuh yang khas (somatotype) untuk menunjang penampilan dan prestasi yang akan dicapai dari setiap individu maupun dalam sebuah tim. Romberz FC merupakan salah satu tim amatir yang bernaung di bawah Pengcab PSSI Bantul. Selain mengandalkan pemain senior, Romberz FC juga mendidik para pemain muda dengan tujuan untuk mengembangkan bakat sepak bola yang ada di Kabupaten Bantul pada umumnya serta desa Pandak khususnya. Bermain pada kompetisi divisi utama dengan target naik ke divisi 
Bantul Super League (BSL) sangatlah penting untuk selalu meninjau kebugaran fisik para pemainnya.

Banyak variasi latihan dan teknik bermain sepak bola yang lebih menarik perhatian para pemain U-17 Romberz FC daripada harus melakukan latihan kondisi fisik yang tentunya sangat menguras tenaga. Sebagai contoh pada sesi latihan teknik shooting ke gawang, antusias para pemain U-17 Romberz FC lebih terlihat, para pemain terlihat senang dan semangat untuk melakukan latihan tersebut, hal itu terbukti dengan banyaknya pemain yang datang untuk mengikuti sesi latihan. Di sisi lain, ketika pelatih menjadwalkan sesi latihan kondisi fisik (lari $8 \mathrm{~km}$ ) untuk meningkatkan daya tahan paru jantung, para pemain terkesan kurang tertarik, terbukti dengan banyaknya jumlah pemain yang tidak datang dengan berbagai macam alasan.

Tidak hanya itu, para pemain U-17 Romberz FC saat bertanding pada kenyataannya sering terjadi kesalahan-kesalahan mendasar saat melakukan umpan silang ataupun penyelesaian akhir di depan gawang. Bola yang seharusnya bisa diumpankan dan dimanfaatkan dengan baik menjadi sia-sia karena kurangnya kekuatan untuk menendang bola sehingga bolanya tidak sampai ke sasaran dan dapat dengan mudah dihalau oleh lawan. Kesalahan tersebut dapat diperbaiki jika dalam sebuah tim benar-benar menerapkan porsi latihan yang pas untuk membangun kekuatan dan daya tahan otot. Pada kenyataannya tim U-17 Romberz FC belum melakukan langkah tersebut, mungkin karena kurang tersedianya sarana latihan yang baik dan tim pelatih kurang mengetahui bentuk variasi latihan dengan menggunakan beban tubuh sendiri untuk melatih kekuatan otot.

Permainan sepak bola mengharuskan para pelakukanya untuk terjadi kontak fisik baik di level senior bahkan di level junior sekalipun. Untuk memenangkan suatu duel kontak fisik tentunya pemain sepak bola harus mempunyai bentuk tubuh yang proporsional. Para pemain U-17 Romberz FC mempunyai bentuk tubuh yang beragam, ada yang kurus, pendek, gemuk, dll. Hal tersebut mengakibatkan para pemain U-17 Romberz FC sering kali kalah saat terjadi kontak fisik, sering dialami oleh pemain gelandang yang mengharuskan menghalau serangan lawan sebelum masuk ke daerah pertahanan tim. Selain di area gelandang, masalah yang harus dibenahi adalah pada pemain belakang. Pemain belakang

Profil Daya Tahan Jantung Paru, Kekuatan Otot Punggung, Kekuatan Otot Tungkai, Fleksibilitas, Komposis Tubuh dan Somatotype Pemain Sepak Bola U-17 Romberz FC Bantul Yogyakarta (Dwi Riyan Susanto dan Fatkurahman Arjuna) 
yang dimiliki tim U-17 Romberz FC berbadan gemuk sehingga terkesan lamban dalam bergerak dan mudah dilewati pemain tim lawan. Dengan adanya masalah tersebut tentunya pelatih harus bijak dalam menentukan porsi latihan.

M. Sajoto, (1988: 10) menyebutkan bahwa keterampilan ataupun keahlian akan menjadi terbatas oleh kondisi fisik yang lemah. Latihan teknik saja tidak akan cukup untuk menambah keterampilan bermain sepak bola, namun hendaknya juga harus melakukan latihan kondisi fisik dan memperhatikan bentuk tubuh. Khusus untuk latihan kebugaran fisik yang menunjang penampilan dalam permainan sepakbola jarang sekali dilakukan oleh para pemain U-17 Romberz FC.

Berkaitan dengan uraian di atas peneliti akan mencoba meneliti tentang "Profil Daya Tahan Jantung Paru, Kekuatan Otot Punggung, Kekuatan Otot Tungkai, Fleksibilitas, Komposisi Tubuh, dan Somatotype Pemain Sepak Bola U-17 Romberz Fc Bantul Yogyakarta".

\section{METODE PENELITIAN}

Penelitian ini adalah penelitian deskriptif, yaitu dalam penelitian hanya ingin menggambarkan situasi yang ada pada saat ini tanpa mengadakan pengujian hipotesis (Sugiyono, 2009: 147). Metode yang digunakan adalah metode survei dengan teknik tes dan pengukuran.

Subjek dalam penelitian ini adalah semua pemain sepak bola U-17 Romberz FC yang berjumlah 21 orang. Variabel dalam penelitian ini adalah daya tahan jantung paru merupakan kemampuan atau kesanggupan fisik pemain U-17 Romberz FC melakukan lari multi stage, kemudian jumlah balikan yang diperoleh dikonversikan ke dalam tabel. Kekuatan otot merupakan kemampuan otot pemain U-17 Romberz FC untuk melawan beban pada otot tungkai dan punggung dengan menggunakan alat leg and back dynamometer. Untuk mengetahui Fleksibilitas pemain U-17 Romberz FC diukur dengan menggunakan fleksometer. Komposisi tubuh merupakan perbandingan berat tubuh tanpa lemak dengan berat tubuh dengan lemak pemain U-17 Romberz FC yang diukur dengan indeks massa tubuh dan pengukuran lemak. Somatotype merupakan bentuk tubuh pemain 
U-17 Romberz FC yang diukur dengan menggunakan metode anthropometri Heath-Carter yang kemudian akan diketahui kategorinya. Teknik analisis data yang digunakan dalam

\section{HASIL PENELITIAN}

Penelitian ini dilakukan di lapangan sepak bola Jodog, Desa Pandak, Kecamatan Gilangharjo, Kabupaten Bantul. Subjek penelitian yang digunakan adalah pemain sepak bola U-17 Romberz FC yang berjumlah 21 orang. Penelitian ini dilaksanakan pada hari Minggu, 11 Mei 2014 pukul 06.30 WIB - 10.00 WIB.

Hasil penelitian tentang tingkat daya tahan jantung paru, kekuatan, fleksibilitas, komposisi tubuh dan somatotype pemain sepak bola U-17 Romberz FC yang datanya diambil pada hari Minggu 11 Mei 2014 terhadap 21 subjek akan dideskripsikan sebagai berikut:

1. Deskripsi Hasil Penelitian Daya Tahan Jantung Paru

Berdasarkan hasil analisis data penelitian yang dilakukan, dapat dideskripsikan dalam bentuk tabel 1 sebagai berikut:

Tabel 1. Penghitungan Tingkat Daya Tahan Jantung Paru

\begin{tabular}{|c|c|c|c|}
\hline \hline No & Kategori & Frekuensi & Persentase $(\%)$ \\
\hline 1. & Rendah sekali & 0 & 0 \\
\hline 2. & Rendah & 3 & 14,29 \\
\hline 3. & Sedang & 9 & 42,86 \\
\hline 4. & Rata - rata & 6 & 28,57 \\
\hline 5. & Baik & 2 & 9,52 \\
\hline 6. & Baik sekali & 1 & 4,76 \\
\hline 7. & Sempurna & 0 & 0 \\
\hline \multicolumn{2}{r}{ Jumlah } & 21 & 100 \\
\hline
\end{tabular}

Dari tabel 1 di atas dapat diketahui bahwa tingkat daya tahan jantung paru yang rendah sebesar 14,29\% (3 pemain), sedang sebesar 42,86\% (9 pemain), rata-rata sebesar 28,57\% (6 pemain), baik sebesar 9,52\% (2 pemain), baik sekali sebesar 4,76 $\%$ (1 pemain). 
1. Deskripsi Hasil Penelitian Kekuatan Otot

Berdasarkan hasil analisis data penelitian yang dilakukan maka dapat dideskripsikan dalam bentuk tabel 2 sebagai berikut :

Tabel 2. Penghitungan Tingkat Kekuatan Otot Punggung

\begin{tabular}{|c|l|c|c|l|}
\hline \hline $\begin{array}{c}\text { No } \\
.\end{array}$ & \multicolumn{1}{|c|}{ Batasan } & Frekuensi & Persentase $(\%)$ & \multicolumn{1}{|c|}{ Kategori } \\
\hline 1. & $>177$ & 0 & 0 & Baik \\
\hline 2. & $126-176$ & 0 & 0 & Sedang \\
\hline 3. & $<125$ & 21 & 100 & Kurang \\
\hline \multicolumn{2}{|c|}{ Jumlah } & 21 & 100 & \\
\hline
\end{tabular}

Dari tabel 2 di atas dapat diketahui bahwa tingkat kekuatan otot punggung yang dalam kategori baik sebesar $0 \%$, kategori sedang sebesar $0 \%$, kategori kurang $100 \%$ (21 pemain).

Tabel 3. Penghitungan Tingkat Kekuatan Otot Tungkai

\begin{tabular}{|c|c|c|c|c|}
\hline \hline No. & Batasan & Frekuensi & Persentase (\%) & Kategori \\
\hline 1. & $>214$ & 5 & 23,81 & Baik \\
\hline 2. & $160-213$ & 6 & 28,57 & Sedang \\
\hline 3. & $<159$ & 10 & 47,62 & Kurang \\
\hline \multicolumn{2}{|c|}{ Jumlah } & 21 & 100 & \\
\hline
\end{tabular}

Berdasarkan tabel 3 di atas dapat diketahui bahwa tingkat kekuatan otot tungkai yang baik sebesar 23,81\% (5 pemain), sedang sebesar 28,57\% (6 pemain), kurang $47,62 \%$ (10 pemain).

2. Deskripsi Hasil Penelitian Fleksibilitas

Dari hasil analisis data penelitian yang dilakukan, dapat dideskripsikan dalam bentuk tabel 4 sebagai berikut : 
Tabel 4. Penghitungan Tingkat Fleksibilitas

\begin{tabular}{|c|l|c|c|}
\hline \hline No & Kategori & Frekuensi & Persentase (\%) \\
\hline 1. & Sangat Baik & 1 & 4,76 \\
\hline 2. & Baik & 4 & 19,05 \\
\hline 3. & Cukup & 7 & 33,33 \\
\hline 4. & Kurang & 7 & 33,33 \\
\hline 5. & Sangat Kurang & 2 & 9,52 \\
\hline \multicolumn{2}{|r|}{ Jumlah } & 21 & 100 \\
\hline
\end{tabular}

Berdasarkan tabel 4di atas dapat diketahui bahwa tingkat fleksibilitas yang berkategori sangat baik sebesar 4,76 \% (1 pemain), baik sebesar 19,05\% (4 pemain), cukup sebesar 33,33\% (7 pemain), kurang sebesar 33,33\% (7 pemain), sangat kurang sebesar $9,52 \%$ ( 2 pemain).

3. Deskripsi Hasil Penelitian Komposisi Tubuh

Berdasarkan hasil analisis data penelitian yang dilakukan, dapat dideskripsikan dalam bentuk table 5 sebagai berikut:

Tabel 5. Penghitungan Tingkat Indeks Massa Tubuh

\begin{tabular}{|c|c|c|c|c|c|}
\hline \hline No & Batasan & Frekuensi & Persentase & \multicolumn{2}{|c|}{ Kategori } \\
\hline 1. & $<17.0$ & 4 & 19,05 & $\begin{array}{c}\text { Kekurangan berat } \\
\text { badan tingkat berat }\end{array}$ & Kurus \\
\cline { 1 - 5 } 2. & $17.0-18.5$ & 6 & 28,57 & $\begin{array}{c}\text { Kekurangan berat } \\
\text { tingkat ringan }\end{array}$ & Normal \\
\cline { 1 - 5 } 3. & $18.5-25.0$ & 9 & 42,86 & $\begin{array}{c}\text { Berat badan normal / } \\
\text { ideal }\end{array}$ & \multirow{2}{*}{ Gemuk } \\
\cline { 1 - 5 } 4. & $25.0-27.0$ & 1 & 4,76 & $\begin{array}{c}\text { Kelebihan berat badan } \\
\text { tingkat ringan }\end{array}$ & \\
\cline { 1 - 5 } 5. & $>27.0$ & 1 & 4,76 & $\begin{array}{c}\text { Kelebihan berat badan } \\
\text { tingkat berat }\end{array}$ & \\
\hline \multicolumn{2}{|c|}{ Jumlah } & 21 & 100 & & \\
\hline
\end{tabular}

Profil Daya Tahan Jantung Paru, Kekuatan Otot Punggung, Kekuatan Otot Tungkai, Fleksibilitas, Komposis Tubuh dan Somatotype Pemain Sepak Bola U-17 Romberz FC Bantul Yogyakarta (Dwi Riyan Susanto dan Fatkurahman Arjuna) 
Berdasarkan tabel 5 di atas dapat diketahui bahwa tingkat indeks massa tubuh yang kekurangan berat badan tingkat berat sebesar 19,05 \% (4 pemain), kekurangan berat tingkat ringan sebesar 28,57 \% (6 pemain), berat badan normal/ideal 42,86 \% (9 pemain), kelebihan berat badan tingkat ringan sebesar 4,76 \% (1 pemain), kelebihan berat badan tingkat berat $4,76 \%$ (1 pemain).

Tabel 6. Penghitungan Tingkat Lemak Tubuh

\begin{tabular}{|c|c|l|c|}
\hline \hline No & Kategori & Frekuensi & Persentase \\
\hline 1. & Sangat baik & 3 & 14,29 \\
\hline 2. & Baik & 10 & 47,62 \\
\hline 3. & Cukup & 3 & 14,29 \\
\hline 4. & Kurang & 2 & 9,52 \\
\hline 5. & Kurang sekali & 3 & 14,29 \\
\hline & Jumlah & 21 & 100 \\
\hline
\end{tabular}

Berdasarkan tabel di atas dapat diketahui bahwa tingkat lemak tubuh yang kategori sangat baik sebesar 14,29\% (3 pemain), baik sebesar 47,62 \% (10 pemain), cukup adalah 14,29\% (3 pemain), kurang sebesar 9,52 \% (2 pemain), kurang sekali sebesar $14,29 \%$ (3 pemain).

4. Deskripsi Hasil Penelitian Somatotype

Berdasarkan hasil analisis data penelitian yang dilakukan, ditentukan kategori somatotype yang diperlukan secara umum. Hasil ini nantinya akan digunakan dalam menentukan letak koordinat dan kategori somatotype secara khusus. Deskripsi analisis hasil penelitian yang dilakukan dengan perhitungan manual didapatkan hasil sebagai berikut: 
Tabel 7. Hasil Perhitungan Somatotype secara Manual

\begin{tabular}{|c|c|c|c|}
\hline $\begin{array}{c}\text { No. } \\
\text { Responden }\end{array}$ & Endomorphy & Mesomorph & Ectomorph \\
\hline 1. & 3,5 & 0,5 & 3,00 \\
\hline 2. & 2 & 1 & 3,00 \\
\hline 3. & 2 & 1 & 3,50 \\
\hline 4. & 2,5 & 2 & 2,00 \\
\hline 5. & 1,5 & 0,5 & 4,00 \\
\hline 6. & 2 & 0,5 & 4,50 \\
\hline 7. & 1,5 & 0,5 & 4,50 \\
\hline 8. & 1,5 & 0,5 & 5,50 \\
\hline 9. & 1,5 & 0,5 & 4,50 \\
\hline 10. & 1,5 & 0,5 & 4,00 \\
\hline 11. & 1 & 0,5 & 5,00 \\
\hline 12. & 4,5 & 1 & 1,00 \\
\hline 13. & 5 & 4 & 0,50 \\
\hline 14. & 4 & 2,5 & 1,00 \\
\hline 15. & 1,5 & 0,5 & 5,50 \\
\hline 16. & 2 & 0,5 & 5,00 \\
\hline 17. & 1,5 & 0,5 & 4,50 \\
\hline 18. & 1,5 & 0,5 & 6,00 \\
\hline 19. & 2,5 & 0,5 & 3,50 \\
\hline 20. & 1,5 & 0,5 & 4,00 \\
\hline 21. & 2 & 0,5 & 5,00 \\
\hline
\end{tabular}

Berdasarkan hasil perhitungan somatotype secara manual di atas dapat diperoleh hasil kategori somatotype dari pemain Romberz FC sebagai berikut:

\section{Endomorphic Ectomorph}

Endomorphic ectomorph adalah ectomorph lebih dominan dan endomorph lebih besar daripada mesomorph. Pada pengambilan data yang berjumlah 21 orang, terdapat 4 pemain yang mempunyai tipe tubuh endomorphic ectomorph. Untuk mencari tipe tubuh di atas digunakan koordinat somatocart seperti ditunjukkan pada tabel berikut: 
Tabel 8. Koordinat Endomorphic Ectomorph

\begin{tabular}{|l|l|c|l|}
\hline No. & Nama Sampel & Koordinat & Kategori \\
\hline 6 & Septian & $\mathrm{X}=2,5 \mathrm{Y}=-5,5$ & Endomorphic Ectomorph \\
\hline 16 & Dimas & $\mathrm{X}=3 \mathrm{Y}=-6$ & Endomorphic Ectomorph \\
\hline 19 & Reza & $\mathrm{X}=1 \mathrm{Y}=-5$ & Endomorphic Ectomorph \\
\hline 21 & Yosafat & $\mathrm{X}=3 \mathrm{Y}=-6$ & Endomorphic Ectomorph \\
\hline \multicolumn{3}{|c|}{ Jumlah $: 19,05 \%$} \\
\hline
\end{tabular}

\section{Balanced Ectomorph}

Balanced ectomorph adalah ectomorph lebih dominan endomorph dan mesomorph sama rendahnya. Pada pengambilan data yang berjumlah 21 orang, terdapat 13 pemain yang mempunyai tipe tubuh balanced ectomorph. Untuk mencari tipe tubuh di atas digunakan koordinat somatocart seperti ditunjukkan pada tabel berikut:

Tabel 9. Koordinat Balanced Ectomorph

\begin{tabular}{|l|l|ll|l|}
\hline No. & Nama Sampel & \multicolumn{2}{|c|}{ Koordinat } & Kategori \\
\hline 2. & Bagas & $\mathrm{X}=1 \quad \mathrm{Y}=-3$ & Balanced Ectomorph \\
\hline 3. & Joko & $\mathrm{X}=1,5 \quad \mathrm{Y}=-3,5$ & Balanced Ectomorph \\
\hline 5. & Budi & $\mathrm{X}=2,5 \mathrm{Y}=-4,5$ & Balanced Ectomorph \\
\hline 7. & Apri & $\mathrm{X}=3 \quad \mathrm{Y}=-5$ & Balanced Ectomorph \\
\hline 8. & Arfian & $\mathrm{X}=4 \quad \mathrm{Y}=-6$ & Balanced Ectomorph \\
\hline 9. & Dhika & $\mathrm{X}=3 \quad \mathrm{Y}=-5$ & Balanced Ectomorph \\
\hline 10. & Dwi & $\mathrm{X}=2,5 \quad \mathrm{Y}=-4,5$ & Balanced Ectomorph \\
\hline 11. & Deni & $\mathrm{X}=-3 \quad \mathrm{Y}=0$ & Balanced Ectomorph \\
\hline 14. & Dhani & $\mathrm{X}=4 \quad \mathrm{Y}=-6$ & Balanced Ectomorph \\
\hline 15. & Faisal & $\mathrm{X}=3 \quad \mathrm{Y}=-5$ & Balanced Ectomorph \\
\hline 17. & Gatot & $\mathrm{X}=4,5 \quad \mathrm{Y}=-6,5$ & Balanced Ectomorph \\
\hline 18. & Ifan & $\mathrm{X}=2,5 \quad \mathrm{Y}=-4,5$ & Balanced Ectomorph \\
\hline 20. & Husni & Jumlah $: 61,90 \%$ \\
\hline \multicolumn{4}{|l}{} \\
\hline
\end{tabular}

\section{Balanced Endomorph}

Balanced endomorph adalah endomorph lebih dominan dan ectomorph dan mesomorph sama rendahnya. Pada pengambilan data yang berjumlah 21 orang, 
terdapat 2 pemain yang mempunyai tipe tubuh balanced endomorph. Untuk mencari tipe tubuh di atas digunakan koordinat somatocart seperti ditunjukkan pada tabel berikut :

Tabel 10. Koordinat Balanced Endomorphic

\begin{tabular}{|l|c|l|l|}
\hline No. & Nama Sampel & Koordinat & Kategori \\
\hline 4. & Nanda & $\mathrm{X}=-0,5 \mathrm{Y}=-0,5$ & Balanced Endomorphic \\
\hline 12. & Arif & $\mathrm{X}=-3,5 \mathrm{Y}=-3,5$ & Balanced Endomorphic \\
\hline \multicolumn{3}{|c|}{ Jumlah $: 9,52 \%$} \\
\hline
\end{tabular}

\section{Balanced Mesomorph}

Balanced mesomorph adalah mesomorph lebih dominan dan ectomorph dan endomorph sama rendahnya. Pada pengambilan data yang berjumlah 21 orang, terdapat 1 pemain yang mempunyai tipe tubuh balanced mesomorph. Untuk mencari tipe tubuh di atas digunakan koordinat somatocart seperti ditunjukkan pada tabel berikut :

Tabel 11. Koordinat Balanced Mesomorph

\begin{tabular}{|l|l|c|c|}
\hline No. & Nama Sampel & Koordinat & Kategori \\
\hline 1 & Wahyu & $\mathrm{X}=-0,5 \mathrm{Y}=-5,5$ & Balanced Mesomorphic \\
\hline \multicolumn{3}{|c|}{ Jumlah : 4,76\% } \\
\hline
\end{tabular}

\section{Mesomorph Endomorph}

Mesomorph endomorph adalah endomorph lebih dominan dan mesomorph lebih besar daripada ectomorph. Pada pengambilan data yang berjumlah 21 orang, terdapat 1 pemain yang mempunyai tipe tubuh mesomorph endomorph. Untuk mencari tipe tubuh di atas digunakan koordinat somatocart seperti ditunjukkan pada tabel berikut:

Tabel 12. Koordinat Mesomorphic Endomorph

\begin{tabular}{|l|l|c|c|}
\hline No. & Nama Sampel & Koordinat & Kategori \\
\hline 13 & Nanang & $\mathrm{X}=-4,5 \mathrm{Y}=2,5$ & Mesomorphic Endomorph \\
\hline \multicolumn{2}{|c|}{ Jumlah : 4,76\% } \\
\hline
\end{tabular}

Profil Daya Tahan Jantung Paru, Kekuatan Otot Punggung, Kekuatan Otot Tungkai, Fleksibilitas, Komposis Tubuh dan Somatotype Pemain Sepak Bola U-17 Romberz FC Bantul Yogyakarta (Dwi Riyan Susanto dan Fatkurahman Arjuna) 
Hasil analisis data menunjukkan bahwa somatotype pemain U-17 romberz FC mempunyai tipe tubuh endomorph ectomorph sebanyak 4 pemain atau sebesar 19,05 $\%$, tipe tubuh balanced ectomorph sebanyak 13 pemain atau sebesar $61,90 \%$, tipe tubuh balanced endomorph sebanyak 2 pemain atau 9,52\%, tipe tubuh balanced mesomorph sebanyak 1 pemain atau 4,76\%, dan tipe tubuh mesomorph endomorph sebanyak 1 pemain atau 4,76\%. Untuk selengkapnya dapat dilihat pada tabel berikut:

Tabel 13. Kategori Somatotype

\begin{tabular}{|c|c|c|c|}
\hline No. & Kategori Somatotype & Jumlah & Persentase (\%) \\
\hline 11 & Endomorph Ectomorph & 4 & 19,05 \\
\hline 22 & balanced ectomorph & 13 & 61,90 \\
\hline 33 & balanced endomorph & 2 & 9,52 \\
\hline 44 & balanced mesomorph & 1 & 4,76 \\
\hline 55 & mesomorph endomorph & 1 & 4,76 \\
\hline
\end{tabular}

\section{PEMBAHASAN}

1. Daya Tahan Jantung Paru

Daya tahan paru pemain U-17 Romberz FC yang berada dalam kategori rendah sebesar 14,29\%, sedang sebesar 42,86 \%, rata-rata sebesar 28,57\%, baik sebesar 9,52 $\%$, baik sekali sebesar 4,76 \%. Daya tahan jantung paru akan memengaruhi berapa lama pemain akan mampu bermain dalam lapangan. Pemain yang mempunyai daya tahan jantung paru yang baik akan mampu untuk bermain selama 90 menit sebaliknya jika seorang pemain mempunyai daya tahan jantung paru rendah, akan cepat kehabisan tenaga sebelum pertandingan selesai.

Dari hasil penelitian di atas masih ada pemain yang memiliki kategori yang rendah. Hal ini mengharuskan bagi pemain maupun pelatih untuk memperbaiki dan meningkatkan daya tahan jantung paru tersebut. Secara keseluruhan pemain Romberz FC memiliki daya tahan jantung paru yang sedang, dikarenakan kurangnya sesi latihan khusus untuk program latihan daya tahan jantung paru. Jika dilihat dari angka VO2 max rata-rata pemain U-17 Romberz FC hanya dibawah $45 \mathrm{ml} / \mathrm{kg} / \mathrm{min}$, masih terpaut jauh dari rata-rata ukuran VO2 max pemain sepakbola Indonesia yaitu sekitar 55 
$\mathrm{ml} / \mathrm{kg} / \mathrm{min}$. oleh sebab itu, sangat perlu adanya peningkatkan intensitas latihan daya tahan jantung paru untuk meningkatkan VO2 max agar mampu bertanding selama 90 menit secara total.

\section{Kekuatan Otot Punggung dan Otot Tungkai}

Kekuatan otot punggung pemain sepak bola U-17 Romberz FC berada dalam kategori kurang $100 \%$, sedangkan tingkat kekuatan otot tungkai yang dalam kategori baik sebesar 23,81\%, sedang sebesar 28,57\%, kurang sebesar 47,62\%.

Hasil di atas menunjukkan bahwa kekuatan otot punggung dan otot tungkai berada kategori kurang dan sedang. Keadaan ini masih jauh dari harapan untuk dapat memiliki kekuatan otot punggung dan kekuatan otot tungkai yang baik sebagai pemain sepak bola. Kurangnya tingkat kekuatan otot para pemain U-17 Romberz FC sangatlah bisa dimaklumi, dikarenakan sesi latihan yang dilakukan hanya tiga kali dalam seminggu. Hal tersebut menyebabkan porsi-porsi latihan kekuatan otot sangat kurang, karena pada sesi latihan sering kali lebih mengutamakan latihan tekhnik dan taktik. Padahal latihan kekuatan otot tungkai dan punggung bisa dilakukan dengan cara sederhana yakni dengan gerakan lunge, squat, back up, dll.

Pemain harus mampu berdiri kuat dan seimbang dalam melakukan gerak yang luas dalam permainan sepak bola. Kekuatan yang baik akan mendorong pemain bergerak dan bertahan dengan baik. Kekuatan otot tungkai akan berpengaruh pada kecepatan lari kelincahan, shooting, dan kemampuan melakukan teknik dasar dengan bola. Otot tungkai menjadi tumpuan yang utama dala permainan sepak bola. Pemain harus mampu melakukan umpan dan tembakan agar mampu memainkan permainan bola yang baik dan melakukan penyelesaian ke gawang dengan baik pula.

\section{Fleksibilitas}

Fleksibilitas pemain U-17 Romberz FC yang berkategori sangat baik sebesar 4,76 $\%$, baik sebesar 19,05\%, cukup sebesar 33,33\%, kurang sebesar 33,33\%, sangat kurang sebesar 9,52\%. Hasil penelitian menunjukan bahwa tingkat fleksibilitas masih di antara kategori kurang dan cukup. Hal tersebut bisa terjadi pada pemain sepak bola U-17 Romberz FC dikarenakan kurangnya arahan stretching saat memulai dan 
mengakhiri sesi latihan maupun pertandingan. Selama ini yang terlihat di lapangan setiap kali selesai latihan maupun pertandingan para pemain hanya duduk-duduk di pinggir lapangan sambil menunggu evaluasi yang akan dilakukan tanpa melakukan cooling down dan stretching. Hal tersebut sangatlah jelas akan memengaruhi fleksibilitas para pemain, karena untuk melatih fleksibilitas salah satunya adalah dengan stretching.

Beberapa ahli mengungkapkan bahwa fleksibilitas yang baik akan memberikan keluasaan dalam bergerak. Komponen-komponen biomotor akan sangat dipengaruhi oleh tingkat fleksibilitas. Pemain yang memiliki tingkat fleksibilitas yang baik, maka pemain tersebut akan bergerak dengan nyaman dalam ruang gerak yang maksimal. Fleksibilitas ini sebagian besar dimiliki oleh pemain yang masih berusia muda. Pergerakan antarsendi, otot, ligamen dan tendo pun masih memiliki kemungkinan untuk lebih diingkatkan, sehingga sangat mencolok jika pemain sepak bola yang masih muda sebagian besar memiliki tingkat fleksibilitas yang lebih baik dibandingkan dengan seniornya. Pergerakan yang leluasa dan lincah ini akan membantu pemain untuk dapat memindahkan bola dengan baik.

4. Komposisi Tubuh

Indeks massa tubuh pemain sepak bola U-17 Romberz FC yang kekurangan berat badan tingkat berat sebesar 19,05\%, kekurangan berat tingkat ringan sebesar 28,57\%, berat badan normal/ideal $42,86 \%$, kelebihan berat badan tingkat ringan sebesar 4,76 \%, kelebihan berat badan tingkat berat 4,76 \%. Tingkat lemak tubuh pemain U-17 Romberz FC yang masuk dalam kategori sangat baik sebesar 14,29 \%, baik sebesar 47,62 \%, cukup adalah 14,29 \%, kurang sebesar 9,52 \%, kurang sekali sebesar 14,29\%.

Tingkat masa tubuh akan menjadi modal awal untuk dapat bermain sepak bola dengan baik. Banyak orang memandang orang gemuk akan mengalami kesulitan untuk bergerak dan mengubah arah secara eksplosif sehingga orang gemuk identik dengan gerakan yang lambat. Kemampuan bergerak dengan cepat menjadi faktor pendukung permainan sepak bola yang cepat. Berbeda dengan pemain yang memiliki tubuh yang kurus, mereka pasti lebih diuntungkan dengan pergerakan yang lebih eksplosif. Meskipun demikian, pemain tersebut akan cenderung dipandang sebelah mata oleh 
pemain lawan karena mudah untuk ditaklukkan. Oleh sebab itu seorang pemain sepak bola seharusnya memiliki perpaduan tubuh yang ideal untuk menyelaraskan antara pergerakan eksplosif dan kontak fisik yang pasti terjadi dalam permainan sepak bola.

\section{Somatotype}

Hasil analisis data menunjukkan bahwa somatotype pemain U-17 Romberz FC mempunyai tipe tubuh endomorph ectomorph sebanyak 4 pemain atau sebesar 19,05\%, tipe tubuh balanced ectomorph sebanyak 13 pemain atau sebesar 61,90\%, tipe tubuh balanced endomorph sebanyak 2 pemain atau 9,52\%, tipe tubuh balanced mesomorph sebanyak 1 pemain atau 4,76\%, dan tipe tubuh mesomorph endomorph sebanyak 1 pemain atau 4,76 \%. Secara keseluruhan pemain U-17 Romberz FC memiliki tipe tubuh balanced ectomorph yang lebih dominan. Hal tersebut kurang ideal untuk ukuran pemain sepak bola. Seorang pemain sepak bola seharusnya lebih condong bertipe tubuh mesomorph endomorph seperti yang diungkapkan oleh (Kevin Norton, 1996: 163). Dengan adanya hasil tersebut, pemain U-17 Romberz FC harus memeperhatikan pola makan dan gizi yang baik agar mencapai bentuk tubuh yang ideal dan proporsional.

Pemain sepak bola U-17 Romberz FC menunjukan hasil somatotype yang sebagian besar bertipe balanced ectomorph. Tipe tubuh tersebut cenderung langsing, lemah, dan tubuh kecil halus. Dalam hal ini pemain sepak bola dengan posisi tertentu memiliki kecenderungan tipe tubuh yang berbeda dikarenakan adanya perbedaan tugas dalam permainan. Perbedaan tipe tubuh antara penjaga gawang, pemain belakang, pemain tengah dan penyerang wajar terjadi. Hal ini dikarenakan mereka memiliki fungsi dan tugas yang berbeda. 


\section{KESIMPULAN}

Berdasarkan hasil penelitian dan pembahasan yang telah dipaparkan dapat diambil kesimpulan sebagai berikut:

1. Profil daya tahan jantung paru pemain U-17 Romberz FC yang berada dalam kategori rendah sebesar $14,29 \%$, sedang sebesar $42,86 \%$, rata-rata sebesar $28,57 \%$, baik sebesar $9,52 \%$, baik sekali sebesar 4,76\%.

2. Profil kekuatan otot punggung pemain U-17 Romberz FC yang berada dalam kategori kurang yaitu sebesar $100 \%$. Tingkat kekuatan otot tungkai yang berada dalam kategori baik sebesar 23,81\%, sedang sebesar 28,57\%, kurang 47,62\%.

3. Profil fleksibilitas pemain U-17 Romberz FC yang berada dalam kategori sangat baik sebesar 4,76 \%, baik sebesar 19,05\%, cukup sebesar 33,33\%, kurang sebesar 33,33\%, sangat kurang sebesar $9,52 \%$.

4. Profil komposisi tubuh pemain U-17 Romberz FC ditinjau dari tingkat indeks massa tubuh yang berada dalam kategori kekurangan berat badan tingkat berat sebesar 19,05 $\%$, kekurangan berat tingkat ringan sebesar 28,57 \%, berat badan normal/ideal 42,86\%, kelebihan berat badan tingkat ringan sebesar $4,76 \%$, Kelebihan berat badan tingkat berat $4,76 \%$. Tingkat lemak tubuh berada dalam kategori sangat baik sebesar 14,29\%, baik sebesar 47,62 \%, cukup adalah 14,29\%, kurang sebesar 9,52\%, kurang sekali sebesar $14,29 \%$.

5. Profil somatotype pemain U-17 Romberz FC mempunyai tipe tubuh endomorph ectomorph sebanyak 4 pemain atau sebesar 19,05\%, tipe tubuh balanced ectomorph sebanyak 13 pemain atau sebesar 61,90\%, tipe tubuh balanced endomorph sebanyak 2 pemain atau 9,52\%, tipe tubuh balanced mesomorph sebanyak 1 pemain atau 4,76\%, dan tipe tubuh mesomorph endomorph sebanyak 1 pemain atau 4,76\%. 


\section{DAFTAR PUSTAKA}

Bompa. (1994). Periodization Theory and Metodology of Training. New York: Hull Publishing Company.

Mochammad Sajoto. (1988). Pembinaan Kondisi Fisik dalam Olahraga. Jakarta: Departemen Pendidikan dan Kebudayaan Direktorat Jenderal Pendidikan Tinggi Obyek Pengembangan Lembaga Pendidikan Tenaga Kependidikan.

Kevin Norton \& Tim Olds. (1996). Anthropometrica. Sydney: University of New South Wales Press.

Soeharsono. (1993). Penelitian Calon Atlet dengan Anthropometri. Yogyakarta: IKIP Yogyakarta.

Sugiyono. (2009). Metode Penelitian Kuantitatif, Kualitatif, dan R\&D. Bandung: CV Alfabeta.

Sugiyono. (2013). Metode Penelitian Pendidikan. Bandung: CV Alfabeta.

Yusuf Hadisasmita dan Arip Syarifuddin. (1996). Ilmu Kepelatihan Dasar. Jakarta: Depdikbud. 